\title{
Resilience and Its Relationship With Occupational Stress and Professional Quality of Life Among Nurses in COVID-19 Isolation Wards
}

\author{
Ali Mostafazadeh \\ Khoy University of Medical Sciences \\ Somayyeh Ghorbani-Sani \\ Khoy University of Medical Sciences \\ Najmadin Seyed-Mohammadi \\ Tabriz University of Medical Sciences \\ Kazhal Ghader-jola \\ Urmia university of medical sciences \\ Zeinab Habibpour ( $\nabla$ habibpoor_z@khoyums.ac.ir) \\ Khoy University of Medical Sciences
}

\section{Research Article}

Keywords: Stress, Resilience, Professional quality of life, Coronavirus disease 2019, Nurse

Posted Date: February 25th, 2021

DOl: https://doi.org/10.21203/rs.3.rs-240339/v1

License: @ (i) This work is licensed under a Creative Commons Attribution 4.0 International License. Read Full License 


\section{Abstract}

Background: Nurses' direct and continuous contact with patients afflicted by coronavirus disease 2019 (COVID-19) causes them stress due to fear over affliction and reduces their professional quality of life (PQOL). Resilience has potential protective effects against different stressors. This study aimed to assess resilience and its relationship with occupational stress (OS) and PQOL among nurses in COVID-19 isolation wards.

Methods: This descriptive-analytical study was conducted in 2020. Participants were nurses in the COVID-19 isolation wards of healthcare centers affiliated to Khoy University of Medical Sciences, Khoy, Iran. In total, 158 eligible nurses were recruited through a census. Data were collected using a researcher-made demographic questionnaire, the short version of the ConnorDavidson Resilience Scale, the Nursing Stress Scale, and the PQOL Scale. Data analysis was performed using the SPSS software (v. 16.) and through the independent-sample $t$ test, one-way analysis of variance, Pearson's correlation analysis, and linear regression analysis.

Results: The total mean scores of resilience and OS were $26.19 \pm 6.2$ (in the possible range of $0-40$ ) and $73.3 \pm 14.5$ (in the possible range of 34-136), respectively. The mean scores of the compassion satisfaction, job burnout, and secondary traumatic stress dimensions of PQOL were respectively 38.02 $\pm 8.16,30.84 \pm 5.45$, and $27.66 \pm 6.13$, (all in the possible range of 10-50). Most participants experienced moderate OS (57.9\%). The mean scores of participants' resilience and OS had no significant relationship with their demographic characteristics $(P>0.05)$. Resilience had significant negative relationship with OS $(r=-0.376, P<0.001)$ and significant positive relationship with the compassion satisfaction dimension of PQOL $(r=0.373$; $P<0.001)$. Resilience was also a significant predictor of $O S$ and the compassion satisfaction dimension of $P Q O L(P<0.001)$.

Conclusion: Nurses' OS can be reduced through resilience-promoting strategies such as development of their social support network, improvement of their optimism, and provision of resilient role models and quality resilience-related education.

\section{Introduction}

Communicable diseases, such as coronavirus disease 2019 (COVID-19), are the most ancient health problems for human beings and are still a major health problem throughout the world despite substantial medical advances in disease prevention and management ${ }^{1}$. COVID-19 is a pneumonia-like communicable disease caused by Severe Acute Respiratory Syndrome Coronavirus 2 (SARS-COVID-2). The main symptoms of the disease are respiratory and gastrointestinal problems. In severe cases, the disease appears as self-limiting pneumonia, acute respiratory distress, septic shock, or multiple organ dysfunction syndrome ${ }^{2}$. COVID-19 was first diagnosed in December 2019 in Wuhan, China, and then, rapidly spread throughout the world and turned into the COVID-19 pandemic ${ }^{3}$. According to the statistics provided by the World Health Organization, there were 72 million patients with COVID-19 and more than 1.65 relevant deaths until December 17, 2020. COVID-19 is most prevalent in the United States, India, Brazil, Russia, and France so that more than $50 \%$ of the approved cases of the disease are in these countries. The number of patients with COVID-19 and the number of deaths due to the disease in Iran were respectively 1.13 million and 53000 until December 17, $2020^{4}$.

As key members of healthcare delivery teams, nurses are in the frontline of care delivery to patients with COVID-19. Nurses' direct and continuous contact with afflicted patients exposes them to the high risk of affliction by COVID-19 and hence, they experience severe stress and have concerns over affliction by COVID-19 or its transmission to others ${ }^{5}$. Recent studies show that 60-70\% of nurses who care for patients with COVID-19 experience moderate to severe occupational stress (OS) ${ }^{6,7}$.

OS is associated with many different consequences for nurses. For instance, it reduces their professional quality of life (PQOL)

${ }^{8,9}$. PQOL refers the positive and negative emotions individuals experience due to their work as helper ${ }^{10}$. It has three main dimensions, namely compassion satisfaction, job burnout, and secondary traumatic stress ${ }^{11}$. Studies showed that OS had significant negative relationship with nurses' quality of work life ${ }^{12}$ and the compassion satisfaction dimension of PQOL, while it had significant positive relationship with the job burnout and the secondary traumatic stress dimensions of PQOL ${ }^{13}$. On the 
other hand, staff with low PQOL have poorer organizational identity, job satisfaction, and occupational performance and are more likely to quit their job 14,15 .

Resilience is a significant factor affecting nurses' perceived stress ${ }^{16}$. By definition, resilience is durability against injuries and life-threatening conditions as well as active participation in the environment which enables individuals to maintain homeostasis in stressful conditions ${ }^{17,18}$. Resilience results in optimism and improves quality of life and self-efficacy among nurses ${ }^{19}$. A study on Korean nurses reported a significant negative relationship between resilience and OS ${ }^{20}$. Another study in Iran revealed that resilience training significantly reduced OS among critical care nurses ${ }^{21}$.

Despite the significant effects of OS and resilience on PQOL, there are limited data about their effects on PQOL among nurses in COVID-19 isolation wards. Therefore, the present study was designed and made in order to narrow this gap. The aim of the study was to assess resilience and its relationship with OS and PQOL among nurses in COVID-19 isolation wards.

\section{Methods}

Design

This descriptive-analytical study was conducted in 2020 .

Participants

Study population consisted of all nurses in the COVID-19 isolation wards of healthcare centers affiliated to Khoy University of Medical Sciences, Khoy, Iran. In total, 158 eligible nurses were recruited to the study through a census. Inclusion criteria were perfect self-reported physical and mental health, bachelor's degree or higher in nursing, and direct contact with COVID-19 patients as a hospital nurse for at least one month. The only exclusion criterion was no response to at least $20 \%$ of the items of the study instruments. Sample size was calculated with a coefficient of resilience-PQOL correlation of 0.13922 , a confidence

interval of 0.95 (i.e. a ${ }^{Z_{1-\alpha / 2}}$ of 1.96), and a power of 0.8. The sample size calculation formula (Fig. 1) showed that 158 nurses were needed for the study.

\section{Data collection}

Data were collected using a researcher-made demographic questionnaire, the short version of the Connor-Davidson Resilience Scale, the Nursing Stress Scale, and the PQOL Scale.

The short version of the Connor-Davidson Resilience Scale was developed in 2003 for resilience assessment. It has ten items scaled on a five-point Likert scale as follows: 0: "Not true at all"; 1: "Rarely true"; 2: "Sometimes true"; 3: "Often true"; and 4: "True nearly all of the time". The possible total score of the scale is $0-40$, with higher scores standing for greater resilience ${ }^{17}$. A former study confirmed the content validity and the reliability of this scale and reported that its Cronbach's alpha was $0.82{ }^{23}$.

The Nursing Stress Scale was developed in 1981 and contains 34 items in seven dimensions about stressful conditions for nurses, namely death and dying (seven items), conflict with physicians (five items), inadequate preparation (three items), lack of support (three items), conflict with other nurses (five items), workload (six items), and uncertainty concerning treatment (five items). Items are scaled on a four-point scale as follows: 1: "Never"; 2: "Occasionally"; 3: "Frequently"; and 4: "Very frequently". The possible total score of the scale is $34-136$ and is interpreted as follows: $\leq 68$ : mild stress; $69-103$ : moderate stress; $\geq 104$ : severe stress ${ }^{24}$. A former study confirmed the validity and reliability of the Persian version of this scale and reported a testretest correlation coefficient of $0.74{ }^{25}$.

PQOL was measured using the PQOL Scale. This scale has thirty items in three ten-item dimensions, namely compassion satisfaction, job burnout, and secondary traumatic stress. Items are scaled on a five-point scale from 1 ("Never") to 5 ("Very often"). The possible total score of the dimensions is 10-50 and is interpreted as follows: $\leq 22$ : low compassion satisfaction, job burnout, and secondary traumatic stress; 23-41: moderate compassion satisfaction, job burnout, and secondary traumatic 
stress; and $\geq 42$ : high compassion satisfaction, job burnout, and secondary traumatic stress ${ }^{11}$. There is no total score for this scale. A study in Iran confirmed the content validity and reliability of this scale and reported a Cronbach's alpha of $0.89^{26}$.

For data collection, study instruments were provided to participants and they were asked to complete and return them in their next work shift.

The SPSS software (v. 16.0) was used for data analysis. The relationship of resilience with OS and PQOL was examined through the Pearson's correlation analysis and the linear regression analysis. Moreover, the relationship of demographic characteristics with resilience, OS, and PQOL was examined using the independent-sample $t$ test or the one-way analysis of variance. The level of significance was set at less than 0.05 .

The Ethics Committee of Khoy University of Medical Sciences, Khoy, Iran, approved this study (code: IR.KHOY.REC.1399.017). Participants were individually informed about the voluntariness of participation, anonymity of the instruments, and confidentiality of data management. Written informed consent was also obtained from all of them.

\section{Results}

In total, 158 nurses working in COVID-19 isolation wards participated in this study. The means of their age and work experience were $32.57 \pm 6.32$ and $8.88 \pm 5.97$ years, respectively. Most participants aged $20-29$ years $(53.16 \%)$, were female (50.64\%) and married (53.8\%), held bachelor's degree in nursing (94.9\%), had conditional permanent employment (57.6\%), and had a work experience of $1-5$ years $(60.12 \%)$. Table 1 shows their demographic characteristics.

The means of participants' resilience and OS were $26.19 \pm 6.2$ (in the possible range of $0-40$ ) and $73.3 \pm 14.5$ (in the possible range of 34-136), respectively. The mean scores of their PQOL were 38.02 \pm 8.16 in the compassion satisfaction dimension, $30.84 \pm 5.45$ in the job burnout dimension, and $27.66 \pm 6.13$ in the secondary traumatic stress dimension (all in the possible range of $10-50$ ). The level of participants' OS was mild in $40.4 \%$ of cases, moderate in $57.9 \%$ of cases, and severe in just one case.

The results of the independent-sample $t$ test and the one-way analysis of variance showed no significant relationship between participants' demographic characteristics and the mean scores of their resilience, OS, and the job burnout and the secondary traumatic stress dimensions of PQOL $(P>0.05)$. However, the mean score of the compassion satisfaction dimension of their PQOL had significant relationship with their educational level and official position (Table 1).

The highest and the lowest dimensional mean scores of $\mathrm{PQOL}$ in the $0-100$ range were respectively related to the compassion satisfaction dimension (70.06) and the secondary traumatic stress dimension (55.32) (Table 2).

The Pearson's correlation analysis showed that the mean score of resilience had significant negative relationship with the mean scores of OS and all its dimensions $(P<0.05)$ except for the lack of support dimension $(P>0.05)$. Moreover, the mean score of resilience had significant positive relationship only with the compassion satisfaction dimension of $P Q O L(P<0.001)(T a b l e ~ 2)$. 
Table 1

Participants' demographic characteristics and their relationships with resilience, OS, and PQOL dimensions

\begin{tabular}{|c|c|c|c|c|c|c|c|c|c|c|c|c|}
\hline \multirow[t]{3}{*}{ Characteristic } & & \multirow[t]{3}{*}{$\mathrm{N}(\%)$} & \multirow{2}{*}{\multicolumn{2}{|c|}{ Resilience }} & \multirow{2}{*}{\multicolumn{2}{|c|}{ Stress }} & \multicolumn{6}{|l|}{ PQOL } \\
\hline & & & & & & & \multicolumn{2}{|c|}{$\begin{array}{l}\text { Compassion } \\
\text { satisfaction }\end{array}$} & \multicolumn{2}{|c|}{ Job burnout } & \multicolumn{2}{|c|}{$\begin{array}{l}\text { Secondary } \\
\text { traumatic } \\
\text { stress }\end{array}$} \\
\hline & & & Mean & $\mathrm{p}$ & Mean & $\mathrm{p}$ & Mean & $\mathrm{p}$ & Mean & $\mathrm{p}$ & Mean & $\mathrm{p}$ \\
\hline \multirow[t]{3}{*}{ Age (Years) } & $20-29$ & $\begin{array}{l}84 \\
(53.16)\end{array}$ & 26.6 & 0.66 & 75.5 & 0.5 & 37.05 & 0.3 & 30.35 & 0.65 & 26.97 & 0.61 \\
\hline & $30-39$ & $\begin{array}{l}55 \\
(34.81)\end{array}$ & 25.65 & & 72.01 & & 37.85 & & 31.32 & & 28.23 & \\
\hline & $\geq 40$ & $\begin{array}{l}19 \\
(12.03)\end{array}$ & 26.89 & & 72.42 & & 40.57 & & 30.47 & & 27.47 & \\
\hline \multirow[t]{2}{*}{ Gender } & Male & $\begin{array}{l}78 \\
(49.36)\end{array}$ & 26.21 & 0.95 & 69.9 & 0.08 & 38.02 & 0.99 & 31.05 & 0.48 & 28.12 & 0.18 \\
\hline & Female & $\begin{array}{l}80 \\
(50.64)\end{array}$ & 26.14 & & 74.7 & & 38.05 & & 30.35 & & 26.58 & \\
\hline \multirow[t]{2}{*}{$\begin{array}{l}\text { Marital } \\
\text { status }\end{array}$} & Single & $\begin{array}{l}73 \\
(46.2)\end{array}$ & 26 & 0.77 & 73.74 & 0.77 & 36.68 & 0.12 & 31.07 & 0.68 & 27.19 & 0.46 \\
\hline & Married & $\begin{array}{l}85 \\
(53.8)\end{array}$ & 26.3 & & 72.95 & & 39.11 & & 30.65 & & 28.04 & \\
\hline \multirow[t]{2}{*}{$\begin{array}{l}\text { Educational } \\
\text { level }\end{array}$} & Bachelor's & $\begin{array}{l}150 \\
(94.9)\end{array}$ & 26.12 & 0.46 & 73.28 & 0.95 & 37.54 & 0.007 & 30.94 & 0.28 & 27.67 & 0.95 \\
\hline & $\begin{array}{l}\text { Master's } \\
\text { and higher }\end{array}$ & $8(5.1)$ & 27.33 & & 73.66 & & 46.66 & & 29 & & 27.5 & \\
\hline \multirow[t]{4}{*}{$\begin{array}{l}\text { Employment } \\
\text { status }\end{array}$} & Permanent & $\begin{array}{l}35 \\
(22.15)\end{array}$ & 24.94 & 0.46 & 74.11 & 0.94 & 38.11 & 0.99 & 30.22 & 0.72 & 27.74 & 0.79 \\
\hline & Contractual & $\begin{array}{l}19 \\
(12.02)\end{array}$ & 25.94 & & 74.31 & & 38.42 & & 30.21 & & 28.47 & \\
\hline & $\begin{array}{l}\text { Conditional } \\
\text { permanent }\end{array}$ & $\begin{array}{l}91 \\
(57.6)\end{array}$ & 26.85 & & 72.59 & & 37.78 & & 31.34 & & 27.04 & \\
\hline & $\begin{array}{l}\text { Mandatory } \\
\text { service }\end{array}$ & $\begin{array}{l}13 \\
(8.22)\end{array}$ & 27.53 & & 72.23 & & 38.07 & & 31.61 & & 28.53 & \\
\hline \multirow{4}{*}{$\begin{array}{l}\text { Work } \\
\text { experience } \\
\text { (Years) }\end{array}$} & $1-5$ & $\begin{array}{l}95 \\
(60.12)\end{array}$ & 26.21 & 0.82 & 75.95 & 0.49 & 36.82 & 0.16 & 30.21 & 0.75 & 26.8 & 0.42 \\
\hline & $6-10$ & $\begin{array}{l}32 \\
(20.25)\end{array}$ & 25.62 & & 70.9 & & 36.65 & & 31.62 & & 28.5 & \\
\hline & $11-15$ & $\begin{array}{l}24 \\
(15.18)\end{array}$ & 26.04 & & 71.95 & & 40.8 & & 31.16 & & 28.83 & \\
\hline & $16-20$ & $\begin{array}{l}17 \\
(10.75)\end{array}$ & 27.41 & & 73.35 & & 39.58 & & 30.41 & & 26.52 & \\
\hline \multirow[t]{2}{*}{$\begin{array}{l}\text { Official } \\
\text { position }\end{array}$} & Head nurse & $\begin{array}{l}5 \\
(3.17)\end{array}$ & 26.65 & 0.66 & 74.82 & 0.6 & 34.34 & 0.028 & 32.08 & 0.3 & 29 & 0.31 \\
\hline & Nurse & $\begin{array}{l}153 \\
(96.83)\end{array}$ & 26.32 & & 72.92 & & 38.95 & & 30.52 & & 27.32 & \\
\hline
\end{tabular}


Table 2

The mean scores of OS and PQOL and their relationships with resilience

\begin{tabular}{|c|c|c|c|c|c|}
\hline \multicolumn{2}{|c|}{ Variables } & \multirow[t]{2}{*}{ Mean $\pm S D$} & \multirow{2}{*}{$\begin{array}{l}\text { Mean } \\
(0-100)\end{array}$} & \multicolumn{2}{|c|}{ Relationship with resilience } \\
\hline & & & & $r$ & $\mathrm{P}$ \\
\hline \multirow[t]{8}{*}{ os } & Death and dying & $16.14 \pm 3.76$ & 57.64 & -0.252 & 0.007 \\
\hline & Conflict with physicians & $10.4 \pm 2.88$ & 52 & -0.447 & $<0.001$ \\
\hline & Inadequate preparation & $5.47 \pm 1.74$ & 45.58 & -0.274 & 0.008 \\
\hline & Lack of support & $4.93 \pm 1.45$ & 41.08 & 0.04 & 0.669 \\
\hline & Conflict with other nurses & $10.59 \pm 3.47$ & 52.95 & -0.309 & 0.001 \\
\hline & Workload & $13.87 \pm 4.1$ & 57.79 & -0.187 & 0.046 \\
\hline & Uncertainty concerning treatment & $11.86 \pm 2.92$ & 59.3 & -0.338 & 0.000 \\
\hline & Total & $73.3 \pm 14.16$ & 53.89 & -0.376 & 0.000 \\
\hline \multirow[t]{3}{*}{ PQOL } & Compassion satisfaction & $38.02 \pm 8.16$ & 70.06 & 0.373 & 0.000 \\
\hline & Job burnout & $30.84 \pm 5.45$ & 61.68 & 0.046 & 0.63 \\
\hline & Secondary traumatic stress & $27.66 \pm 6.13$ & 55.32 & -0.151 & 0.109 \\
\hline
\end{tabular}

The results of the linear regression analysis revealed that resilience significantly predicted $14 \%$ of the total variance of OS ( $P<$ $0.001)$ and $25 \%$ of the total variance of the compassion satisfaction dimension of $P Q O L(P<0.001)$. However, resilience was not a significant predictor of the job burnout and the secondary traumatic stress dimensions of PQOL $(P>0.05)(T a b l e 3)$. 
Table 3

The results of the linear regression analysis to determine the predictors of OS and PQOL

\begin{tabular}{|c|c|c|c|c|c|c|c|c|c|c|}
\hline Dependent variable & Model & $\begin{array}{l}\text { Std. } \\
\text { Error }\end{array}$ & $\mathbf{R}$ & $\mathbf{R}^{2}$ & $\mathbf{F}$ & Sig. & B & $\beta$ & $t$ & Sig. \\
\hline \multirow[t]{2}{*}{ OS } & Constant & 5.94 & 0.38 & 0.14 & 18.45 & $<.001$ & 96.27 & - & 17.52 & $<.001$ \\
\hline & Resilience & 0.2 & & & & & $\overline{0} .88$ & $\overline{0} \cdot 38$ & -4.3 & $\begin{array}{l}< \\
0.001\end{array}$ \\
\hline \multirow[t]{4}{*}{$\begin{array}{l}\text { Compassion } \\
\text { satisfaction }\end{array}$} & Constant & 3.1 & 0.5 & 0.25 & 4.39 & $<.001$ & 25.18 & - & 8.1 & $<.001$ \\
\hline & $\begin{array}{l}\text { Educational } \\
\text { level }\end{array}$ & 3.2 & & & & & 6.92 & 0.19 & 2.16 & 0.033 \\
\hline & $\begin{array}{l}\text { Official } \\
\text { position }\end{array}$ & 1.8 & & & & & 4.3 & 0.21 & 2.37 & 0.019 \\
\hline & Resilience & 0.12 & & & & & 0.49 & 0.373 & 4.25 & $\begin{array}{l}< \\
0.001\end{array}$ \\
\hline \multirow[t]{2}{*}{ Job burnout } & Constant & 2.32 & 0.05 & 0.002 & 0.23 & 0.63 & 29.79 & - & 13.34 & $<.001$ \\
\hline & Resilience & 0.08 & & & & & 0.04 & 0.046 & 0.48 & 0.63 \\
\hline \multirow[t]{2}{*}{$\begin{array}{l}\text { Secondary traumatic } \\
\text { stress }\end{array}$} & Constant & 2.49 & 0.15 & 0.022 & 2.62 & 0.109 & 31.57 & - & 12.7 & $<.001$ \\
\hline & Resilience & 0.09 & & & & & -0.15 & 0.543 & -1.61 & 0.1 \\
\hline
\end{tabular}

\section{Discussion}

This study assessed resilience and its relationship with OS and PQOL among nurses in COVID-19 isolation wards. Findings showed that the mean score of participants' resilience was $26.19 \pm 6.2$ (in the possible range of $0-40$ ), denoting moderate to great resilience. In line with this finding, former studies on nurses in intensive care units and COVID-19 isolation wards also reported relatively great resilience 23,27 and moderate to great resilience 28,29 .

Study findings also showed that the mean score of OS was $73.3 \pm 14.5$ (in the possible range of 34-136), denoting moderate level of OS among participants. Moreover, more than $57.9 \%$ of participants had moderate OS. In line with this finding, a former study during the Severe Acute Respiratory Syndrome epidemic in Singapore revealed that more than half of the nurses had moderate stress ${ }^{30}$. Another study reported moderate to severe stress among nurses in COVID-19 isolation wards ${ }^{31}$. The main reasons for the moderate to high levels of OS among nurses in COVID-19 isolation wards include their heavy workload, uncertainty over treatment effectiveness, fear over affliction by COVID-19 and its transmission to others, use of warm and heavy personal protective equipment, and continuous use of mask ${ }^{32}$, which put them at risk for different psychological disorders 20,33 , 34 . Contrary to these findings, two former studies in China and Egypt reported the very high level of OS among nurses in COVID19 isolation wards ${ }^{35,36}$. This contradiction is probably due to the greater number of female nurses in those studies and the significantly higher levels of OS among female nurses ${ }^{36}$.

We also found that participants suffered from moderate to severe job burnout and secondary traumatic stress. A former study reported that nurses and physicians in COVID-19 wards experienced moderate job burnout and compassion satisfaction ${ }^{37}$. Another study showed that during the COVID-19 pandemic, healthcare providers had moderate compassion satisfaction, job burnout, and secondary traumatic stress ${ }^{38}$. These findings are due to the fact that nurses are in the frontline of care delivery to patients with COVID-19 and hence, are at great risk for psychological disorders such as depression, which in turn increases their fatigue and reduces their PQOL ${ }^{39}$. Moreover, the mean score of compassion satisfaction in the present study was relatively greater than the mean score of nurses' compassion satisfaction in studies conducted before the COVID-19 pandemic ${ }^{22,40}$. This 
contradiction may be due to the fact that individuals experience good feelings when they see that their services are beneficial to others, particularly in critical conditions 41,42 .

Our findings also showed that resilience among nurses in COVID-19 isolation wards had significant negative relationship with their OS, denoting that more resilient nurses had lower OS. Two former studies also reported lower levels of OS among nurses with greater resilience ${ }^{43}, 44$. Resilience enables nurses to use effective coping skills for effectively coping and working in stressful conditions ${ }^{31}$. In overall, more resilient individuals are more optimistic, consider problems as opportunities for learning and development, and have greater recovery abilities, more flexible thinking skills, greater perseverance, greater stamina, greater problem-solving skills, and greater conflict management skills ${ }^{32}$. Therefore, OS among nurses in COVID-19 isolation wards can be reduced through interventions for promoting their resilience.

We also found that the mean score of resilience had significant positive relationship with the mean score of the compassion satisfaction of PQOL. A former study also reported that mental health professionals with higher compassion satisfaction experienced significantly lower levels of psychological tension ${ }^{45}$. These findings can be attributed to the protective effects of resilience against OS.

\section{Limitations}

Study data were collected through the self-report method and hence, might have been subjected to some levels of measurement bias. Moreover, the study was conducted in the COVID-19 isolation wards of healthcare centers affiliated to Khoy University of Medical Sciences, Khoy, Iran, and may not completely be generalizable to nurses in other areas. Studies in other settings and on different healthcare providers, including nursing managers as well as nurses in different hospital wards, are recommended to produce more reliable results.

\section{Conclusion}

This study concludes that nurses in COVID-19 isolation wards have great resilience, moderate OS, and moderate PQOL and their resilience is a significant predictor of their OS and compassion satisfaction. Accordingly, strategies are needed to promote their resilience, reduce their OS, and improve their PQOL. These strategies include development of their social support network, improvement of their optimism, and provision of resilient role models and quality resilience-related education.

\section{Declarations}

\section{Ethical approval and consent to participate}

The current study was conducted in accordance with the Declaration of Helsinki and approved by the Ethical Committee of Khoy University of Medical Sciences, Khoy, Iran (code: IR.KHOY.REC.1399.017). All participation was voluntary, their informed written consent and all data were treated confidentially.

\section{Consent for publication}

Not Applicable.

\section{Availability of data and materials}

The datasets used and/or analyzed during the current study are available from the corresponding author on reasonable request

\section{Competing interests}

The authors declare that they have no competing interest.

\section{Funding}


This work was financially supported by Khoy University of Medical Sciences under Grant No. IR.KHOY.REC.1399.017.

\section{Authors' contributions}

AM designed the study, participated in data analysis and interpretation, and wrote the manuscript. SG assisted in data analysis and interpretation, and critically reviewed the manuscript. NS assisted in data collection and extraction. KG contributed to the data collection, and writing of the manuscript. ZH oversaw the entire study process and participated in the revision and acted as the corresponding author. The final manuscript was read and approved by all authors.

\section{Acknowledgement}

We would like to thank the Research and Technology Administration of Khoy University of Medical Sciences, Khoy, Iran, for its tangible and intangible support for the present study as well as all nurses who participated in the study.

\section{References}

1. Guan W-j, Ni Z-y, Hu Y, Liang W-h, Ou C-q, et al. Clinical characteristics of coronavirus disease 2019 in China. New England Journal of Medicine. 2020.

2. Huang C, Wang Y, Li X, Ren L, Zhao J, et al. Clinical features of patients infected with 2019 novel coronavirus in Wuhan, China. The lancet. 2020; 395(10223): 497-506.

3. Schwartz J, King C-C, Yen M-Y. Protecting health care workers during the COVID-19 coronavirus outbreak-Lessons from Taiwan's SARS response. Clin Infect Dis. 2020.

4. WHO W H O. COVID-19. April 2020; Available from: www.who.int.

5. Mo Y, Deng L, Zhang L, Lang Q, Liao C, et al. Work stress among Chinese nurses to support Wuhan for fighting against the COVID-19 epidemic. Journal of Nursing Management. 2020.

6. Shahrour G,Dardas L A. Acute stress disorder, coping self-efficacy and subsequent psychological distress among nurses amid COVID-19. Journal of nursing management. 2020; 28(7): 1686-1695.

7. Wang H, Liu Y, Hu K, Zhang M, Du M, et al. Healthcare workers' stress when caring for COVID-19 patients: An altruistic perspective. Nursing ethics. 2020; 27(7): 1490-1500.

8. Chegini Z, Asghari Jafarabadi M, Kakemam E. Occupational stress, quality of working life and turnover intention amongst nurses. Nursing in critical care. 2019; 24(5): 283-289.

9. Kent W, Hochard K D, Hulbert-Williams N J. Perceived stress and professional quality of life in nursing staff: How important is psychological flexibility? Journal of Contextual Behavioral Science. 2019; 14: 11-19.

10. Circenis K, Millere I, Deklava L. Measuring the professional quality of life among Latvian nurses. Procedia-Social and Behavioral Sciences. 2013; 84: 1625-1629.

11. Stamm B H, The concise ProQOL manual. 2010, Pocatello, ID: proqol. org.

12. Jafari M, Habibi Houshmand B, Maher A. Relationship of occupational stress and quality of work life with turnover intention among the nurses of public and private hospitals in selected cities of Guilan Province, Iran, in 2016. Journal of health research in community. 2017; 3(3): 12-24.

13. Ortega-Galán Á M, Ruiz-Fernández M D, Lirola M-J, Ramos-Pichardo J D, Ibáñez-Masero O, et al. Professional Quality of Life and Perceived Stress in Health Professionals before COVID-19 in Spain: Primary and Hospital Care. in Healthcare. 2020. Multidisciplinary Digital Publishing Institute.

14. Hursepuny F L, Eka N G A, Lumbantoruan S M. Professional Quality of Life in Emergency and Critical Care Nursing: A Literature Review. UI Proceedings on Health and Medicine. 2017; 2.

15. Kim H-J,Choi H-J. Emergency nurses' professional quality of life: compassion satisfaction, burnout, and secondary traumatic stress. Journal of Korean Academy of Nursing Administration. 2012; 18(3): 320-328.

16. García-Izquierdo M, Meseguer de Pedro M, Ríos-Risquez M I, Sánchez M I S. Resilience as a moderator of psychological health in situations of chronic stress (burnout) in a sample of hospital nurses. Journal of Nursing Scholarship. 2018; 50(2):

Page 9/11 
228-236.

17. Connor K M,Davidson J R. Development of a new resilience scale: The Connor-Davidson resilience scale (CD-RISC). Depression and anxiety. 2003; 18(2): 76-82.

18. Habibpour Z, Mahmoudi H, Nir M S, Areshtanab H N. Resilience and its predictors among the parents of children with cancer: A descriptive-correlational study. Indian journal of palliative care. 2019; 25(1): 79.

19. Hart P L, Brannan J D, De Chesnay M. Resilience in nurses: An integrative review. Journal of nursing management. 2014; 22(6): 720-734.

20. Kim B-N, Oh H-S, Park Y-S. A study of nurses' resilience, occupational stress and satisfaction. Korean Journal of Occupational Health Nursing. 2011; 20(1): 14-23.

21. Babanataj R, Mazdarani S, Hesamzadeh A, Gorji M H, Cherati J Y. Resilience training: Effects on occupational stress and resilience of critical care nurses. International journal of nursing practice. 2019; 25(1): e12697.

22. Gerami Nejad N, Hosseini M, Mousavi Mirzaei S, Ghorbani Moghaddam Z. Association between Resilience and Professional Quality of Life among Nurses Working in Intensive Care Units. Iran Journal of Nursing. 2019; 31(116): 49-60.

23. Salimi S, Pakpour V, Feizollahzadeh H, Rahmani A. Resilience and its association with the intensive care unit nurses' intention to leave their profession. Journal of hayat. 2017; 23(3): 254-265 [In Persian].

24. Gray-Toft P,Anderson J G. The nursing stress scale: development of an instrument. Journal of behavioral assessment. $1981 ; 3(1): 11-23$.

25. Rhezaii S,Fallahi A H M. Evaluating Impact Of Communication Skills Training On Level Of Job Stress Among Nursing Personnel Working At Rehabilitation Centers In Cities\&58; Ray-Tehran-Shemiranat. Tehran University Medical Journal. 2006; 64(1): 21-26.

26. Vagharseyyedin S A, Zarei B, Hosseini M. The role of workplace social capital, compassion satisfaction and secondary traumatic stress in affective organisational commitment of a sample of Iranian nurses. Journal of Research in Nursing. 2018; 23(5): 446-456.

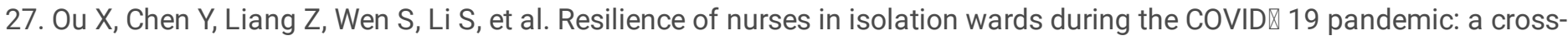
sectional study. Psychology, health \& medicine. 2020: 1-9.

28. Jose S, Dhandapani M, Cyriac M C. Burnout and Resilience among Frontline Nurses during COVID-19 Pandemic: A Crosssectional Study in the Emergency Department of a Tertiary Care Center, North India. Indian Journal of Critical Care Medicine: Peer-reviewed, Official Publication of Indian Society of Critical Care Medicine. 2020; 24(11): 1081.

29. Zhang X. Association of Resilience and Burnout During the COVID-19 Pandemic: Positive and Negative Affect as Mediators in a Cross-Sectional Study of the Frontline Nurses in China. Available at SSRN 3679869. 2020.

30. Koh D, Lim M K, Chia S E, Ko S M, Qian F, et al. Risk Perception and Impact of Severe Acute Respiratory Syndrome (SARS) on Work and Personal Lives of Healthcare Workers in Singapore What Can We Learn? Medical care. 2005: 676-682.

31. Tayyib N A,Alsolami F J. Measuring the extent of stress and fear among Registered Nurses in KSA during the COVID-19 Outbreak. Journal of Taibah University Medical Sciences. 2020.

32. Liu C-Y, Yang Y-Z, Zhang X-M, Xu X, Dou Q-L, et al. The prevalence and influencing factors in anxiety in medical workers fighting COVID-19 in China: a cross-sectional survey. Epidemiology \& Infection. 2020: 1-17.

33. Said R M,El-Shafei D A. Occupational stress, job satisfaction, and intent to leave: nurses working on front lines during COVID-19 pandemic in Zagazig City, Egypt. Environmental Science and Pollution Research. 2020: 1-11.

34. Zhan Y, Ma S, Jian X, Cao Y, Zhan X. The Current Situation and Influencing Factors of Job Stress Among Frontline Nurses Assisting in Wuhan in Fighting COVID-19. Frontiers in Public Health. 2020; 8.

35. Kakemam E, Kalhor R, Khakdel Z, Khezri A, West S, et al. Occupational stress and cognitive failure of nurses and associations with self-reported adverse events: A national cross-sectional survey. Journal of Advanced Nursing. 2019; 75(12): 3609-3618.

36. Kakemam E, Raeissi P, Raoofi S, Soltani A, Sokhanvar M, et al. Occupational stress and associated risk factors among nurses: a cross-sectional study. Contemporary nurse. 2019; 55(2-3): 237-249. 
37. Buselli R, Corsi M, Baldanzi S, Chiumiento M, Del Lupo E, et al. Professional Quality of Life and Mental Health Outcomes among Health Care Workers Exposed to Sars-Cov-2 (Covid-19). International journal of environmental research and public health. 2020; 17(17): 6180.

38. Zhou Q,Zhang X. Influence of workload, mental health and professional quality of life on healthcare workers' hand hygiene behavior in medical aid during COVID-19 pandemic. 2020.

39. Dehkordi A H, Gholamzad S, Myrfendereski S, Dehkordi A H. The Effect of Covid-19 on Anxiety, Quality of Work Life and Fatigue of Health Care Providers in Health Care Centers. 2020.

40. Ruiz-Fernández M D, Pérez-García E, Ortega-Galán Á M. Quality of Life in Nursing Professionals: Burnout, Fatigue, and Compassion Satisfaction. International Journal of Environmental Research and Public Health. 2020; 17(4): 1253.

41. Ruiz-Fernández M D, Ramos-Pichardo J D, Ibáñez-Masero O, Cabrera-Troya J, Carmona-Rega M I, et al. Compassion fatigue, burnout, compassion satisfaction and perceived stress in healthcare professionals during the COVID-19 health crisis in Spain. Journal of clinical nursing. 2020; 29(21-22): 4321-4330.

42. Schwartz C, Meisenhelder J B, Ma Y, Reed G. Altruistic social interest behaviors are associated with better mental health. Psychosomatic medicine. 2003; 65(5): 778-785.

43. Barzilay R, Moore T M, Greenberg D M, DiDomenico G E, Brown L A, et al. Resilience, COVID-19-related stress, anxiety and depression during the pandemic in a large population enriched for healthcare providers. Translational psychiatry. 2020; 10(1): 1-8.

44. Khanmohammadi S, Hajibeglo A, Rashidan M, Bekmaz K. Relationship of resilience with occupational stress among nurses in coronavirus ward of Khatam Al-Anbia Hospital, Gonbad Kavous, 2020. Neuropsychiatry \& Neuropsychology/Neuropsychiatria i Neuropsychologia. 2020; 15.

45. Adeyemo Sunday O, Omoaregba Joyce O, Aroyewun Bushura A, Modebe Vera O, James Bawo O, et al., Experiences of Violence, Compassion Fatigue and Compassion Satisfaction on the Professional Quality of Life of Mental Health Professionals at a Tertiary Psychiatric Facility in Nigeria. 2015.

\section{Figures}

$$
n=\frac{\left(Z_{1-\alpha / 2}+Z_{1-\beta}\right)^{2}}{\omega^{2}}+3
$$

\section{Figure 1}

Sample size calculation formula 